scientists who wished to have more time for preparation for it. The sole motive for such a postponement was therefore the desire to secu e the very best preparation for the Congress and the widest possible participation in its work by scientists of different countries. One thing must be borne in mind in any discussion of the problems of scientific development in the U.S.S.R. The U.S.S.R. is a country of planning. The whole economy of the country, and also the various branches of its cultural and scientific activities are regulated by a definite State plan. Science is planned, not, of course, in the sense that every minute detail of scientific research, etc., is laid down beforehand in a Government Department. That would be ridiculous. But science is planned in the sense that the broad outlines of its development are brought into line with the most urgent requirements of practical life. The prevailing view in the U.S.S.R. is that science must not consider itself a demi-god with the right to choose its own course without any reference to the needs and requirements of the people. On the contrary, the primary object of science is to serve as faithfully as possible the needs of the people, and, indeed, of humanity. Some scientists in foreign countries seem to be inclined to confuse the planning of science, in the above sense, with a lack of scientific freedom. But this is a cardinal error. The planning of science, like planned economy, prevents the waste of human energy and endeavour, and makes it possible to concentrate the greater part of scientific effort on the points of real need of the people and of humanity. The great advantages of such a system are clearly shown by the enormous advance of science in the U.S.S.R. during post-revolutionary years. Indeed, every unbiased observer will testify to the very great prospects for scientific development which exist in the U.S.S.R., such as can be found in scarcely any other country."

\section{The United States Floods}

THE catastrophic inundation of the valley of the River Ohio, which was referred to in NATuRE of January 30 (p. 185), has since assumed even more alarming proportions and threatens to overwhelm in a comprehensive deluge the whole of the Mississippi Valley from the town of Cairo (Illinois) at the junction with the Ohio River right down to the Gulf of Mexico. The flood waters from the latter river are moving onwards, unchecked and uncontrolled, at the rate of 80-90 miles per twenty-four hours. The extent of country involved can be seen from the accompanying map. At the moment of writing, Cairo is just commencing to receive the crest of the wave, which is expected to culminate in a level of $62 \mathrm{ft}$. Thence it will pass on through Memphis (Tennessee), Vicksburg and Natchez (Mississippi) to Baton Rouge and New Orleans (Louisiana). In the Ohio Valley there has been left a track of widespread ruin and desolation, with the water still standing $12 \mathrm{ft}$. deep in the streets of Evansville, just below Louisville. Surveying the disaster at the week-end, the American Red Cross reported 400 people dead, 800,000 homes flooded, more than a million people still homeless and more than a quarter of a million marooned in the upper floors and roofs of their houses or other refuges. The chairman stated with every justification that the American nation is faced with the gravest emergency since the Great War. The material damage is estimated at 400 million dollars $(£ 80,000,000)$. Not less important is the denudation of the valley, from which some $3,000,000$ tons of fertile soil have been swept down-stream by the force of the current.

Orders have been issued from Washington to the Army to prepare plans for the evacuation of the entire civilian population within an area extending fifty miles on each side of the Mississippi, in case of a collapse of the levees with which the river banks are topped. Already 60,000 people have moved to

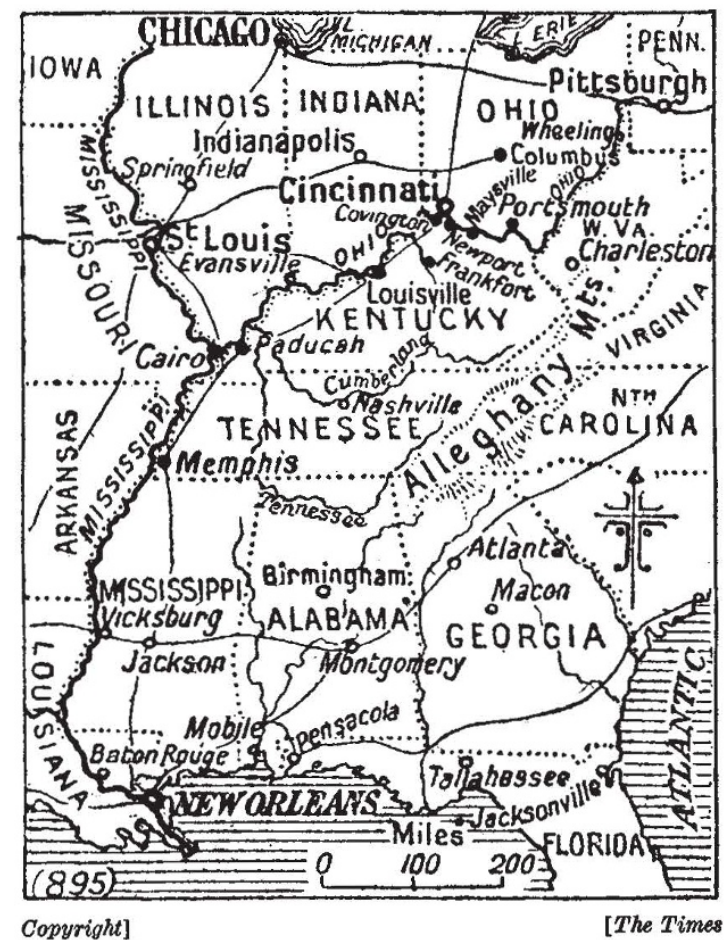

higher ground in Arkansas and 30,000 have left their homes in Missouri. Disease and privation have followed on the heels of the flood. A state of quarantine has been declared in Louisville, where typhoid is prevalent, and 200,000 persons have been inoculated. An explanation put forward to account for the magnitude of the disaster is that the Obio has received as much run-off from rainfall within a fort. night as it usually receives in six months, by reason of the mildness of the season, which has allowed mountain streams to run freely instead of the flow being retarded by the formation of ice and snow, which normally melts slowly during the spring months. Meanwhile, though it is reported that rain has continued to fall heavily in the afflicted area, it is hoped that the worst is past, and that the serious forebodings hitherto entertained will not be realized. 